\title{
Hacia una democracia
}

paritaria. La evolución

de la participación

política de las mujeres

en México y sus entidades

federativas*

* González Oropeza, Manuel, Gilas, Karolina y Báez Silva, Carlos, Hacia una democracia paritaria. La evolución de la participación política de las mujeres en México y sus entidades federativas, México, Tribunal Electoral del Poder Judicial de la Federación, 2016.

Tla-Melaua, revista de Ciencias Sociales. Facultad de Derecho y Ciencias Sociales. Benemérita Universidad Autónoma de Puebla, México / Issn: 1870-6916 / Nueva Época, Año 9, No 39, octubre 2015/marzo 2016, pp. 226-230. 
El libro que nos entregan Manuel González, Karolina Gilas y Carlos Báez es un insumo fundamental para comprender el largo y arduo trayecto que las mujeres han recorrido para ejercer con plenitud sus derechos políticoelectorales. Es, pues, un trabajo integral sobre la participación femenina en el espacio público y sobre la labor de protección jurisdiccional de los derechos de las mujeres en el ámbito electoral.

Seis son los capítulos que integran la obra. El primero, "El sufragio de las mujeres: cigualdad política por decreto o por convicción?", es un estudio histórico de las luchas de las mujeres para ser reconocidas como ciudadanas completas; es decir, como integrantes activas de la democracia por medio del ejercicio efectivo del voto pasivo y activo. El examen de la presencia de las mujeres en el ámbito público inicia en la época de la Independencia. Después, los autores centran su atención en la revista Violetas del Anáhuac, aparecida en 1887, donde, por primera vez, se demandó el sufragio femenino.

No pasan por alto la Revolución mexicana y el papel que tuvieron las mujeres, no sólo como "adelitas", sino como mensajeras, enfermeras o espías. Esta lucha llevó a que varios grupos de mujeres formaran clubes que abrazaron la causa maderista. La actividad política de las mujeres se extendió por todo el país: ahí está la celebración del Primer Congreso Feminista en Yucatán.

Al redactarse la Constitución de 1917, los legisladores, sin embargo, pasaron por alto las demandas de las mujeres y no establecieron su derecho al sufragio. No fue sino hasta en 1947 cuando la Carta Magna se modificó para permitir que las mujeres votaran en comicios municipales. En 1953 se constitucionalizó su derecho a votar y ser votadas en elecciones federales. La crónica de los hechos y el uso de fuentes de archivo son un aporte a la historiografia del movimiento feminista.

En el segundo capítulo, "El debate reubicado: del voto femenino al acceso a cargos", se presenta una exposición sobre las luchas feministas en el mundo y en México. Se diferencian tres olas. La primera abarca de finales del siglo XIX hasta mediados del siglo xx; puso énfasis en el reconocimiento

\footnotetext{
* Politólogo y administrador público por la Facultad de Ciencias Políticas y Sociales de la Universidad Autónoma de México. (etorres.alonso@gmail.com
} 
del derecho al sufragio, en las modificaciones a las leyes sobre relaciones familia y en el mejoramiento de la situación económica de las mujeres. La segunda ola, que se ubica entre los años 1960 y 1970, tuvo como fuente de inspiración los textos de Simone de Beauvoir, Betty Friedan y Kale Millet; se centró en las relaciones entre las esferas pública y privada.

Los resultados de esta ola fueron que los derechos de las mujeres se consideraran como derechos humanos, que ocurriera una transformación parcial de la percepción social de los roles de género y que se facilitara el ingreso de las mujeres a los campos universitario y laboral. Finalmente, en la tercera ola emergieron temas y corrientes como el feminismo social, cultural, multicultural, corporal, entre otros. El feminismo mexicano, por su parte, tuvo una ruta distinta al internacional, acaso debido a las peculiaridades sociales e históricas del país.

Los autores reseñan el ingreso de las mujeres a posiciones de poder. Destacan la conformación de las Cámaras de Diputados y de Senadores, desde 1953 hasta 2015, y enumeran a los grupos de mujeres, surgidos durante la segunda mitad del siglo xx, que impulsaron el debate público sobre los temas de la agenda de las mujeres: autonomía sobre su cuerpo e igualdad de oportunidades. En fin, estudian las alianzas que dichos grupos entablaron con partidos políticos y actores sociales para institucionalizar las demandas del movimiento feminista e implementar acciones afirmativas en materia de equidad de género. Este capítulo cierra con una cronología de 1900 a 2014 con los momentos importantes para el feminismo mexicano.

El capítulo tres, "El falso debate superado: igualdad como equivalencia", es una discusión teórica basada en las corrientes feministas de la igualdad y de la diferencia, en torno a tres preguntas (cuál es la justificación de la necesidad de fomentar la participación de la mujer, cuáles son las acciones para ello, y cuál es la meta a la que se pretende llegar). La primera corriente, el feminismo de la igualdad, afirma que las diferencias entre hombres y mujeres son construcciones sociales, por lo que no hay una esencia de unos u otros.

Los hombres están expuestos a la vida pública, mientras que las mujeres se resguardan en la vida privada. Esta corriente se inscribe en el universalismo de los derechos y quienes se adscriben a ella han trabajado por insertar a la mujer en los espacios públicos. Contrario a esto, el feminismo de la diferencia sostiene que al hacer eso, las mujeres pierden su identidad. Se argumenta que para lograr el empoderamiento de la mujer es preciso reconocer sus diferencias, valores y virtudes y, con ello, realizar una nueva valoración de las características de las personas.

Este feminismo considera que la paridad en los cargos es el objetivo, mientras que el feminismo de la igualdad sostiene que la paridad es un medio. Un rasgo importante que diferencia a ambas corrientes es el lapso de vigencia de la medida para reducir la brecha entre los géneros. El feminismo de igualdad 
considera que debe ser temporal, mientras que para el de la diferencia debe ser permanente. Finalmente, González, Gilas y Báez introducen en este capítulo la discusión sobre la participación de la mujer recurriendo a la teoría de la representación democrática.

"Una historia varias veces contada... la evolución de la cuota en México y su impacto en la representación política de las mujeres", es el título del cuarto capítulo, en donde se presenta una discusión sobre las acciones afirmativas, en particular, las cuotas de género y su evolución en México. Los autores echan mano de las ideas de varios autores como Dahlerup, Fridenvall, Moreira, Johnson, Gerva, Ansolahabere, Aparicio y Langston. Asimismo, proponen una periodización de las cuotas de género en México.

En la primera etapa (1993-2002), se introdujo en la ley electoral la recomendación para los partidos de una cuota de género, sin establecer un porcentaje de candidaturas para las mujeres. Esto ocurrió por dos factores: un incremento de la presencia de mujeres líderes dentro de las organizaciones partidistas que, con razón, buscaban alcanzar puestos de representación popular; como resultado de la reforma electoral de 1993, se pasó de la atención de los temas de diseño institucional a los de equidad en los procesos comiciales.

En 1996 se incluyó, de nuevo a manera de sugerencia, en la ley electoral que los partidos no debían postular a más de setenta por ciento de candidatos de un mismo género. La segunda etapa comprende de 2002 a 2007. En ella se conservaron los porcentajes 70/30, pero la ley mandató su aplicación al nivel de las candidaturas propietarias. De forma adicional, se fortaleció la cuota para las candidaturas por el principio de representación proporcional; las listas debían ir en segmentos de tres candidatos, incluyendo en los tres primeros lugares de la lista a un candidato de género distinto. Finalmente, en la tercera (2007-2011), se incrementó el umbral de treinta a cuarenta por ciento y se modificó la forma de integrar listas de representación proporcional, decretando que debían componerse por segmentos de cinco candidatos y que en cada uno de éstos no se podían incluir más de tres de un mismo género.

El capítulo que sigue, "Una sentencia y un cambio constitucional: SUPJDC-12624/2011", contiene descripciones y análisis de la dinámica del incremento de la presencia femenina en el Congreso Federal, como resultado de las decisiones jurisdiccionales. Como estudio de caso, utiliza la sentencia SUP-JDC-12624/2011, mejor conocida como sentencia "anti-juanitas", la cual ayudó a romper el cerco de la participación de las mujeres y que derivó en una reforma constitucional.

La sentencia, resultado del acuerdo CG327/2011 del Instituto Federal Electoral, por el cual se indicaron los criterios aplicables para el registro de candidaturas para las elecciones de 2011-2012, ordenó la obligación del cumplimiento de la cuota de género por parte de la autoridad electoral administrativa. La sentencia fue antesala de la reforma de 2014 que introdujo 
una nueva etapa de la acción afirmativa: la paridad de género. El artículo 41 constitucional estableció que los partidos políticos deberán postular candidatos, por los principios uni y plurinominal, hombres y mujeres en igualdad de porcentaje para el Congreso federal como para las legislaturas locales.

Además, todas las fórmulas de candidatos deben integrarse por personas del mismo género. Más aún, la paridad debe aplicarse en los sistemas normativos internos de las comunidades indígenas. El principio constitucional se desarrolló en la Ley General de Instituciones y Procedimientos Electorales y en la Ley General de Partidos Políticos.

Finalmente, el capítulo que cierra la obra, "Un avance que no se detiene: la paridad de género en las sentencias del TEPJF", analiza las interpretaciones de la reforma de 2014 que estableció la paridad en las elecciones en función del cumplimiento del principio de paridad, y su aplicación en la esfera municipal y en la integración de los órganos electos. Aquí, los autores se refieren a la aplicación de paridad de género en la postulación de candidatos a nivel municipal, en sus vertientes horizontal (postulaciones de candidatos a presidentes municipales) y vertical (integración de la planilla de candidatos a regidores).

Asimismo, examina la posición de la autoridad jurisdiccional electoral al aceptar la idea de paridad como repartición equilibrada del poder entre los géneros, aunque ello no signifique la igualdad numérica. El tema de paridad marcó el proceso electoral 2014-2015. El capítulo termina con un ilustrativo cuadro con las sentencias relevantes en materia de acciones afirmativas en favor de las mujeres durante el periodo 2003-2015.

En suma, el libro nos ayuda a advertir la ruta y las dificultades que las mujeres han enfrentado para constituirse como ciudadanas plenas y pensar los obstáculos que aún quedan y las estrategias para vencerlos, para lograr integrar a todas y todos a la convivencia democrática y plural. 
